\title{
Obituary
}

\section{In memory of Prof. Dr. Holger Schmid-Schönbein}

Professor Holger Schmid-Schönbein, born on April 6, 1937 in Tübingen, Germany, passed away on December 12, 2017 after a full and creative life. He was an internationally appreciated physiologist and had gained particular merits in the dissemination of Clinical Hemorheology not only in Germany. His perpetual efforts to link clinical physiology with clinical practice significantly improved our understanding of the mechanisms underlying cardiovascular physiology and pathophysiology.

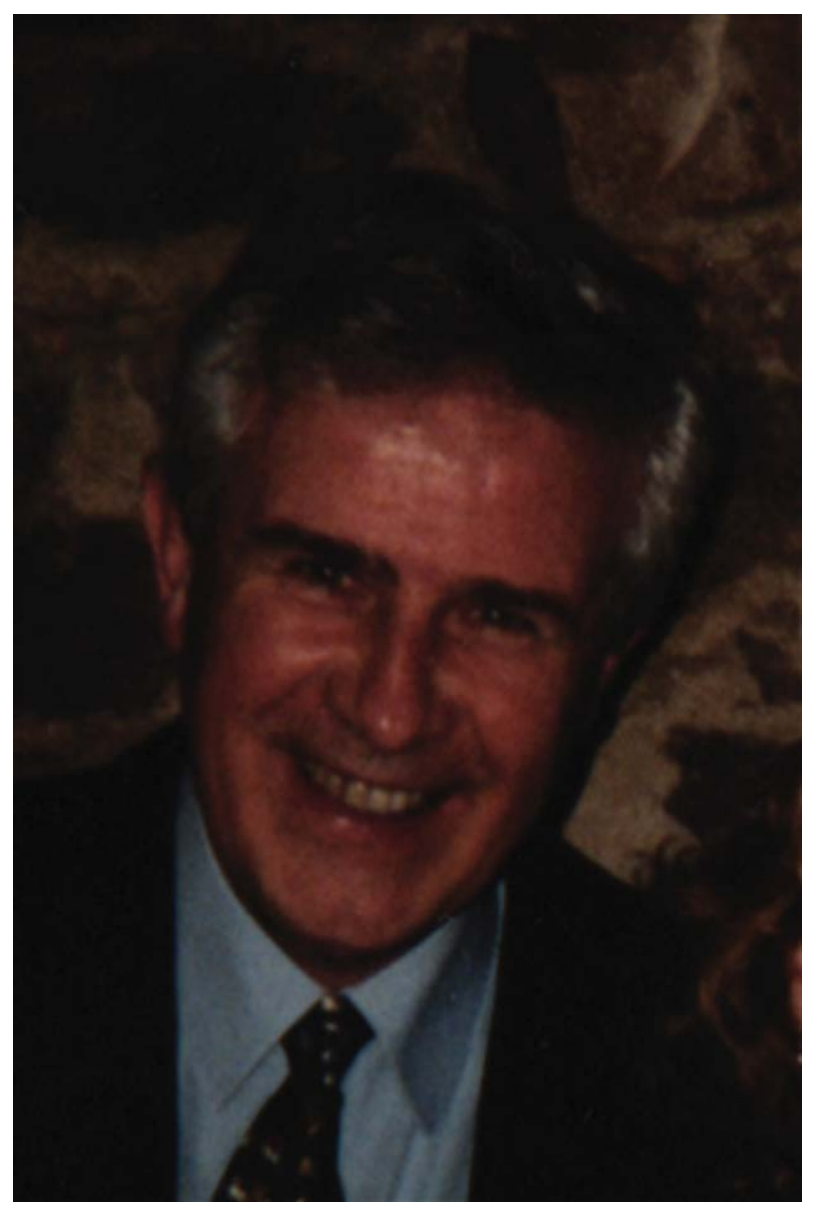

Prof. Dr. med. (MD) Holger Schmid-Schönbein 
The German Society for Clinical Hemorheology and Microcirculation lost one of its most distinguished scientists.

After high-school, Prof. Schmid-Schönbein studied human medicine at the Universities of Tübingen, Göttingen, Kiel and, finally, of Düsseldorf, where he received the degree Medical Doctor (MD) in 1962. Post-graduate studies followed in the Institute of Physiology at the University of Cologne. With a research grant from the Max-Kade-Foundation he attended Harvard Medical School and started with studies in the field of Hemorheology. Returning to Germany, he got an employment at the Institute of Physiology of the University of Munich, where he received the venia legendi in Physiology.

In 1974 the Medical Faculty of the RWTH Aachen offered Schmid-Schönbein

the Chair in Physiology and the position of Director of the Institute of Physiology, which he accepted and held until he was given the emeritus status in 2003. From 1982 to 1984 he was the Dean of the Medical Faculty and under his eloquent guidance the Medical Faculty could successfully establish the Institute for Animal Research.

In his own area of research, hemorheology, Prof. Schmid-Schönbein gained a high reputation for his interdisciplinary approaches combining theoretical models based on mathematical analyses with experimental methods. And everyone in the field took notice when he published.

"Exempla haemorheologica. Das strömende Organ Blut" in 1980, where he excellently explained and demonstrated the decisive role of the micro-circulation and, especially, of capillaries within the network of blood circulation, high-lighting the interactions of blood cells with the vascular walls.

In a collaborative research center for the development of advanced artificial organs (SFB 109), introduced by the German Research Council (DFG) for the period between 1975 and 1987, Prof. Schmid-Schönbein was the Speaker and responsible for the sub-group dealing with all problems concerning blood rheology, coagulation and thrombus formation.

For his achievements in the field of Hemorheology Prof. Schmid-Schönbein received the Fåhraeus-Medal-Award in 1985.
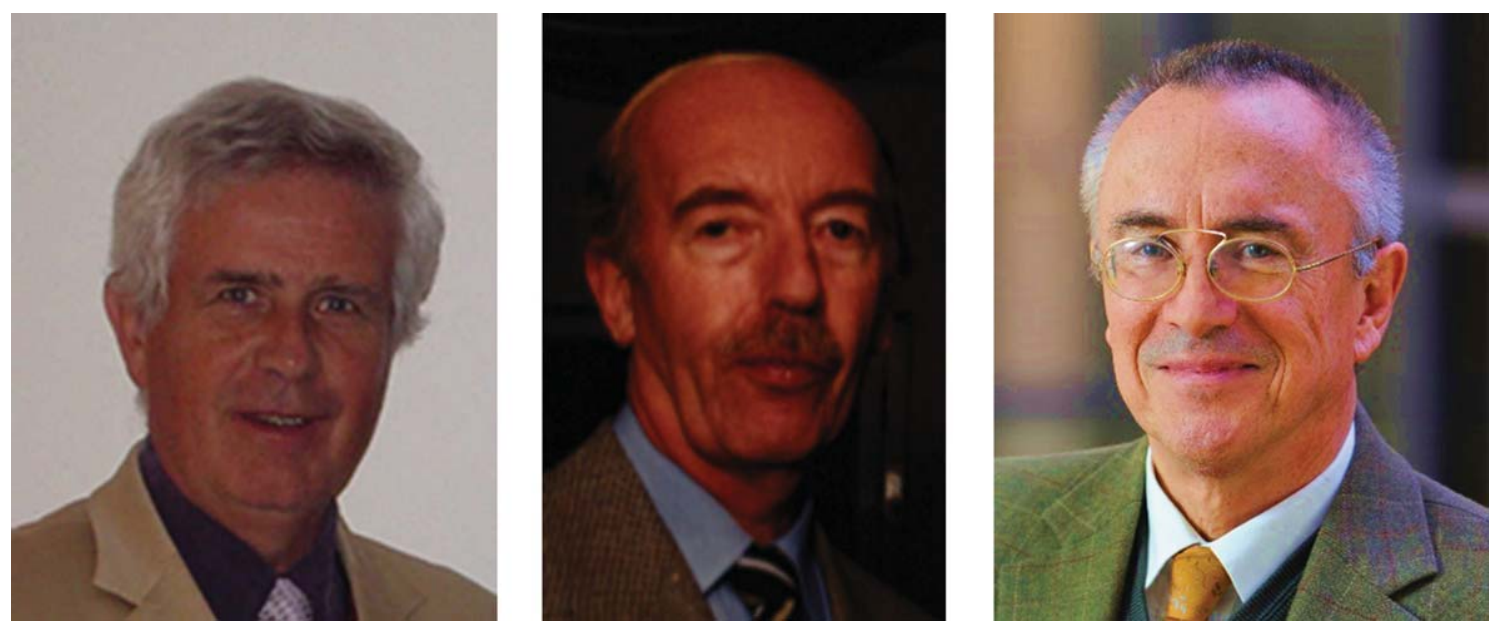

Prof. Holger Schmid-Schönbein together with Prof. Albrecht Ehrly and Prof. Friedrich Jung, the three German Robin-Fåhraeus Awardees, during the European Conference for Clinical Hemorheology and Microcirculation in 2007, when Prof. Schmid-Schönbein was still scientifically active though being Emeritus since 2003.

He will always be honoured and remembered as a great pioneer of Clinical Hemorheology and his memory will be kept in our society. The Hemorheology community will miss him. The loss of Prof. Holger Schmid-Schönbein leaves us with a deep feeling of sadness. 
Rest in peace.

F. Jung

Institute of Biomaterial Science and Berlin-Brandenburg Centre for Regenerative Therapies,

Helmholtz-Zentrum Geesthacht, Teltow,

Germany
R.P. Franke

Central Institute for Biomedical Technology

Dep. Biomaterials,

University of Ulm,

Albert-Einstein-Allee 47,

Ulm,

Germany 